\title{
SHORT-PERIOD FLUCTUATIONS IN THE NUMBERS OF BARNACLE LARVAE, WITH NOTES ON COMPARISONS BETWEEN PUMP AND NET PLANKTON HAULS
}

\author{
By K. A. Pyefinch \\ Formerly Biologist to the Corrosion Committee, \\ British Iron and Steel Research Association. \\ From the Marine Station, Millport
}

(Text-figs. I-7)



\section{INTRODUCTION}

In the course of a series of daily plankton hauls, made over a period of over four years (Pyefinch, I948), indications had been noted of variations in the numbers of barnacle larvae at different phases of the tide. It was also possible that diurnal variations occurred in the numbers of these larvae present near the water surface, and an attempt was therefore made to discover the extent of these variations.

It is clearly essential that an investigation of this character should be quantitative, and hauls were therefore made by pumping water through plankton nets. Hauls made by allowing plankton nets to fish from Keppel Pier during the ebb tide were, however, maintained throughout the period over which the pump hauls were made, so that comparisons could be made between the results obtained by the two methods.

Though the results of the investigation of the possible occurrence of tidal and diurnal variations in the numbers of barnacle larvae in the surface waters cannot be considered to be more than suggestive, the comparisons between pump and net hauls have revealed a number of points of interest, which it seems useful to place on record.

Acknowledgement is made to the Marine Corrosion Sub-Committee of the British Iron and Steel Research Association for their permission to publish 
this work. Grateful acknowledgement is also due to the Scottish Marine Biological Association for the loan of the equipment used, and the author is especially indebted to $\mathrm{Dr} \mathrm{H}$. J. Thomas for his share in the labour of the serial hauls.

\section{METHODS}

Hauls were made using a Standard-Gwynne centrifugal pump, fitted with an armoured suction hose approximately $3 \frac{1}{2}$ in. in external diameter; the delivery hose was also armoured and was approximately $2 \frac{1}{4}$ in. in external diameter. A cylindrical copper rose was fitted to the suction hose; this rose was approximately 7 in. long and 4 in. in diameter (external dimensions) and was drilled with $\frac{3}{8}$ in. holes, $\frac{1}{2}$ in. between centres.

The suction hose hung over the seaward end of the landing stage of Keppel Pier and the water pumped was directed into a plankton net supported over a tank situated on the pier. The rose of the suction hose was adjusted to a constant depth before each haul was made. For the earlier hauls this was $3 \mathrm{ft}$. below the water surface, but for the later hauls (those made from 29 March onwards) the rose was adjusted to a depth of $2 \mathrm{ft}$. below the surface before each haul. This adjustment could only be made approximately, especially when heavy seas were breaking. Hauls made at various depths showed little variation in the numbers of larvae, over the range possible with this pump, so that it is unlikely that the alteration in depth of rose from 3 to $2 \mathrm{ft}$. mid-way through the series of readings described below caused any significant difference in the results obtained.

The capacity of the receiving tank was 3501 ., but the volume of water filtered through the net was usually $3331 .\left(0.3 \mathrm{~m}^{3}\right)$. The volume of water which was pumped through the net was measured and the time taken to pump this volume of water was also recorded. This was done to ensure that approximately the same rate of pumping was maintained throughout, to minimize errors which might arise if gross variations in rate occurred. By adjustment of the water outlet valve and the throttle a reasonably uniform rate of pumping was achieved, of the order of $2001 . / \mathrm{min}$. This is the minimum rate recommended by Wiborg (1948).

Most of the larvae collected were intact and so were readily identified, but there was evidence of some damage during passage through the pump, as isolated naupliar and cyprid appendages occurred occasionally in the hauls; these are rarely seen in hauls made by fishing a net from the pier. Larger planktonic forms (e.g. Calanus) were usually damaged, though it is not impossible to obtain samples of such larger forms using a pump, as Gibbons \& Fraser (1937), using a different type of centrifugal pump, have obtained hauls of much larger planktonic forms than barnacle larvae in an undamaged state.

The site chosen for collecting these pump hauls was by no means ideal, but it was the best possible within reasonable working distance of the laboratory. 
The chief disadvantage was that the rose was immersed very near to a barnaclecovered surface, so that there was a danger that larvae liberated from these barnacles could be taken directly into the suction hose; this seems likely to have occurred on at least one occasion during the sampling. On the other hand, the pump samples were taken as near as possible to the point from which plankton nets are usually fished, so that comparisons between the two types of haul could reasonably be made. It should be pointed out, however, that the currents flowing through the pier are undoubtedly complex, due to the obstruction of the piles, so that conditions cannot, in all probability, be regarded as strictly comparable. Any investigation of inshore planktonic forms seems bound to encounter difficulties of this nature, since hauls must be taken at sites where the hydrodynamic conditions are complex, due to the irregularities of the neighbouring shore.

\section{Serial Hauls}

Three sets of serial hauls, each extending over $24 \mathrm{hr}$. or longer, were made and these were supplemented by other series carried out over shorter periods. The first set of serial hauls was made on II and I2 March, the second set on 23 and 24 March, and the final set from 29 March to I April 1948 .

Table I shows the average numbers of the larval stages of Balanus balanoides, $B$. crenatus and Verruca stroemia during these three periods, as averages for the 3-day period most closely corresponding to the period of the serial haul. These were obtained in hauls made from the pier in the usual way, by fishing a net for I hr. during the ebb tide. The first set of serial pump hauls was thus made during a period when early-stage nauplii predominated, the second set at a time when later-stage nauplii were more abundant, and the third set just when cyprids (particularly those of Balanus balanoides) were beginning to be plentiful.

Table I. Average Numbers of Barnacle Larvae occurring in Net Plankton Hauls during the Periods when Serial Pump Hauls were MADE

\begin{tabular}{|c|c|c|c|c|c|c|c|c|}
\hline & & \multicolumn{7}{|c|}{ Average numbers of larvae present . } \\
\hline & & \multicolumn{6}{|c|}{ Nauplius } & \multirow[b]{2}{*}{ Cyprid } \\
\hline Period & Species & I & II & III & IV & $\mathrm{V}$ & $\mathrm{VI}$ & \\
\hline IO-I2 March & $\begin{array}{l}\text { B. balanoides } \\
B . \text { crenatus } \\
\text { V. stroemia }\end{array}$ & $\begin{array}{r}3845 \\
565 \\
4320\end{array}$ & $\begin{array}{r}20925 \\
4390 \\
5090\end{array}$ & $\begin{array}{r}\mathrm{I} 460 \\
360 \\
1075\end{array}$ & $\begin{array}{l}260 \\
120 \\
600\end{array}$ & $\begin{array}{l}40 \\
40 \\
20\end{array}$ & $\begin{array}{l}0 \\
0 \\
0\end{array}$ & $\begin{array}{l}0 \\
0 \\
0\end{array}$ \\
\hline 22-24 March & $\begin{array}{l}\text { B. balanoides } \\
B . \text { crenatus } \\
V . \text { stroemia }\end{array}$ & $\begin{array}{l}\text { Io } \\
\text { 10 } \\
\text { 10 }\end{array}$ & $\begin{array}{l}175 \\
120 \\
200\end{array}$ & $\begin{array}{r}1065 \\
80 \\
125\end{array}$ & $\begin{array}{r}3290 \\
560 \\
470\end{array}$ & $\begin{array}{r}3235 \\
6 \mathrm{I} 5 \\
4 \mathrm{I} 20\end{array}$ & $\begin{array}{r}4620 \\
743 \\
35\end{array}$ & $\begin{array}{r}215 \\
240 \\
0\end{array}$ \\
\hline 29-3I March & $\begin{array}{l}\text { B. balanoides } \\
B . \text { crenatus } \\
V . \text { stroemia }\end{array}$ & $\begin{array}{r}0 \\
25 \\
5\end{array}$ & $\begin{array}{r}190 \\
185 \\
20\end{array}$ & $\begin{array}{r}405 \\
675 \\
35\end{array}$ & $\begin{array}{r}1745 \\
1705 \\
415\end{array}$ & $\begin{array}{l}\text { III } 5 \\
\text { I705 } \\
4245\end{array}$ & $\begin{array}{r}2895 \\
1490 \\
515\end{array}$ & $\begin{array}{l}9885 \\
205 \\
105\end{array}$ \\
\hline JOURN. MAR. BI & 1. & & & & & & & 23 \\
\hline
\end{tabular}


It was originally hoped that it would be possible to carry out further sets of serial hauls, but the numbers of larvae decreased so considerably after 9 April, that further series showed no promise of profitable results.

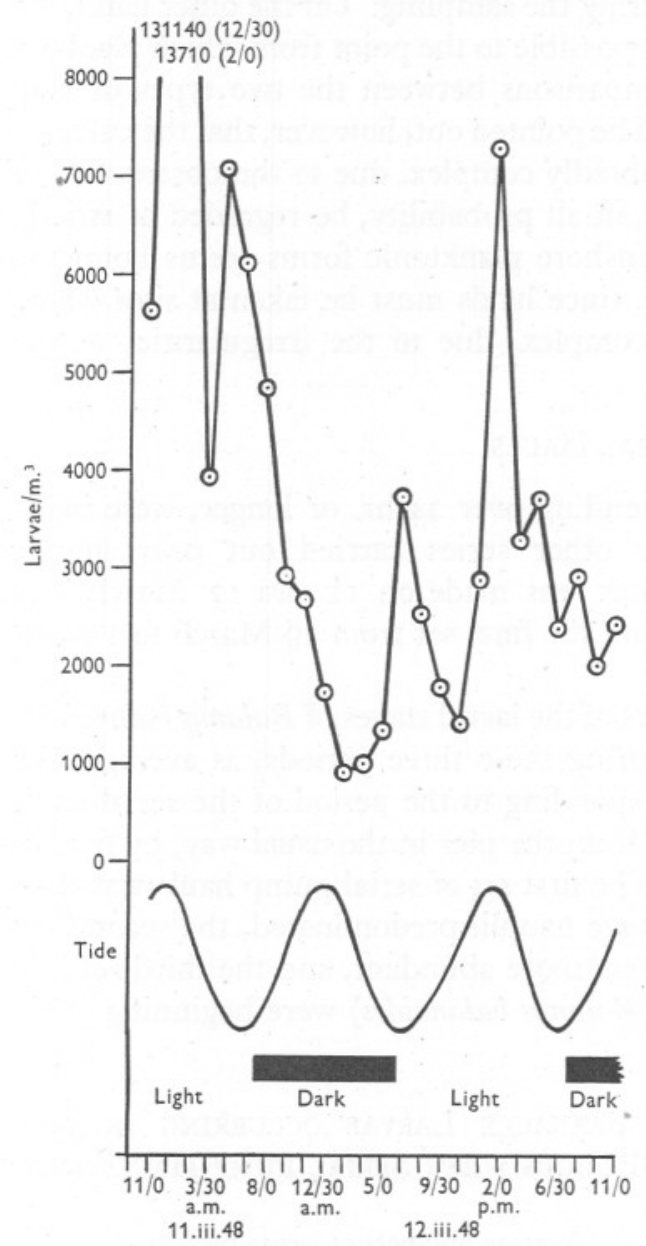

Fig. I. Total barnacle larvae in the serial hauls of I I-I2 March.

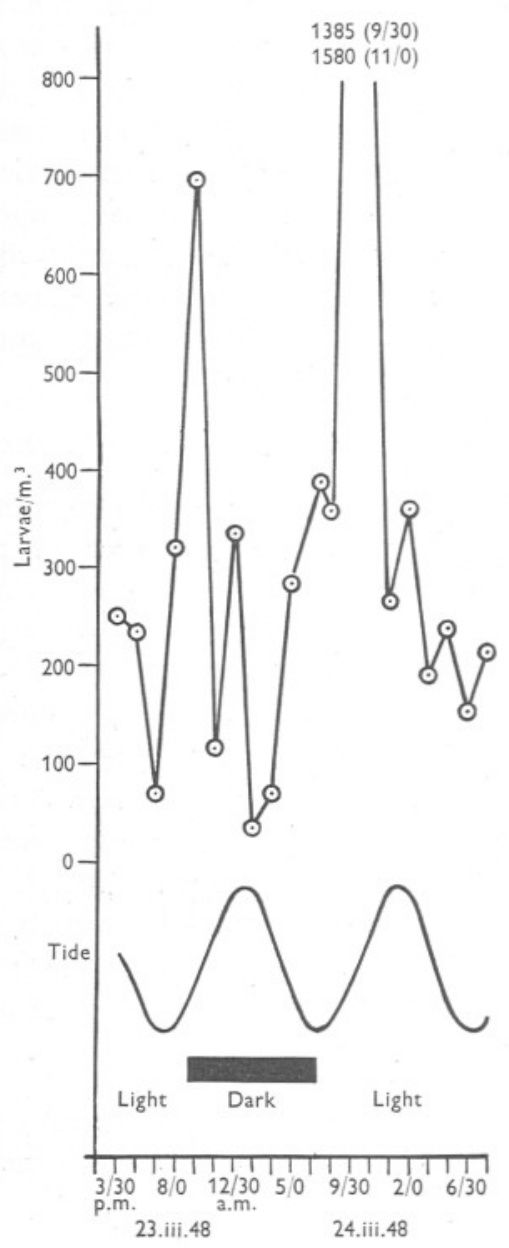

Fig. 2. Total barnacle larvae in the serial hauls of 23-24 March.

Series of II-I2 March. The results of this series are shown in Fig. I. It would appear that the numbers of larvae present in the surface waters are reduced during the hours of darkness and, further, that maximum numbers of larvae are present at high water during the day, but not at high water during the night.

It will be noted that this graph is drawn for 'total nauplii', i.e. all stages present of the three species. A further analysis of these data suggests that the 
generalizations just quoted are too clear cut. The exceptionally heavy haul taken at high water on II March consisted chiefly of the Ist-stage nauplius of $B$. balanoides ( $86 \%$ of the haul), whereas the maximum shown at high water the following day contained no Ist-stage nauplii of $B$. balanoides, but considerable numbers of the 2nd-stage nauplius, supplemented by Ist- and 2ndstage nauplii of $B$. crenatus. It would seem reasonable to suggest that the maximum which occurred on II March was unusual; it may well have been produced by the liberation of nauplii from a small number of $B$. balanoides followed immediately by their uptake into the suction. Moore (I935) states that a single individual of $B$. balanoides can produce $\mathrm{I} 3,000$ nauplii, so that the product of only a few individuals would be needed to give the number of these larvae recorded in this haul.

Series of 23-24 March. The results of these hauls are shown in Fig. 2. The general outline of this curve is less regular than that shown in Fig. I, fluctuations between successive hauls being more marked. This may well be due to the smaller numbers of larvae taken during this series, as it will be noted that the vertical scale of Fig. 2 is ten times that of Fig. I.

Apart from the fact that the numbers of larvae taken during the hours of darkness were again rather smaller than those taken during the day, there is little correspondence between Figs. I and 2. In the present series there is no suggestion of a significant maximum at high water, the largest numbers of larvae being taken during the flood tide, both at night.and during the day. The constitution of these two maximum hauls was similar, i.e. roughly the same proportion of the naupliar stages of each of the three species occurred in each haul. It is thus possible that, as this series of hauls was taken at a time when later-stage nauplii were abundant, this difference in behaviour is genuine and that the migrations of these stages differ from those of the earlier stages. In view, however, of the results obtained from the third series (see pp. 357-60) and of the considerable fluctuations that can occur in larval numbers over short periods of time (see p. 362), this suggestion does not seem likely to be correct.

Though cyprids (particularly those of $B$. balanoides) were obtained in these hauls, the records of their occurrence have been omitted from Fig. 2, as the numbers obtained were so small.

Series of 29 March-I April. This series of hauls"was made at the time when the cyprids of $B$. balanoides were beginning to become abundant; separate graphs have therefore been given of the total nauplii (Fig. 3) and the total cyprids (Fig. 5).

Fig. 3 presents a record which is even less regular than that of Figs. I and 2. The numbers of larvae present during the night were again rather lower than those present by day, but otherwise maxima seem to be irregular in their incidence. During the first night of the series a maximum occurred just after darkness had fallen, at the time of low water, whereas at the corresponding time $24 \mathrm{hr}$. later, naupliar numbers were practically at their minimum, but 
there were signs of a maximum near the time of low water during the third night. During the day two maxima occurred at low water, two during the flood tide and one when the tide was ebbing.

Further analysis into naupliar stages does not reveal any regularity. Fig. 4 shows the occurrence of later-stage nauplii over the same period (naupliar stages III-VI inclusive were counted as 'later-stage' nauplii for $B$. balanoides

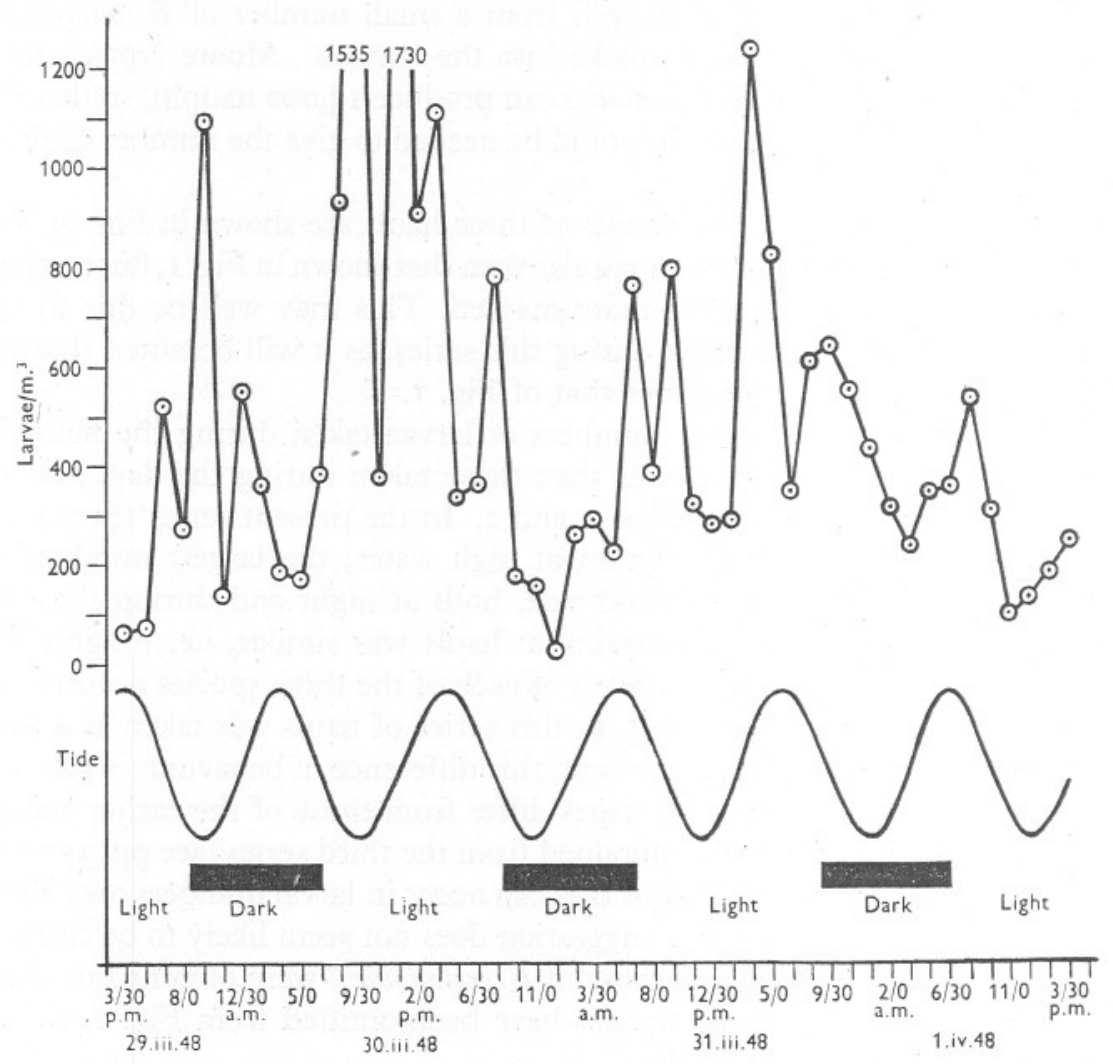

Fig. 3. Total barnacke larvae in the serial hauls of 29 March-I April.

and $B$. crenatus and naupliar stages IV-VI for Verruca stroemia). The only point of interest about this figure is that the numbers of Balanus balanoides and $B$. crenatus larvae tend to decrease over the later part of the period, whereas the larvae of Verruca stroemia are then definitely more abundant. It is possible that the weather may have been an important factor in producing this result. For the last $24 \mathrm{hr}$. of this series of hauls, there was a gale from the south and west and it is possible that this churned the water sufficiently to bring numbers of Verruca larvae into the surface layers. 

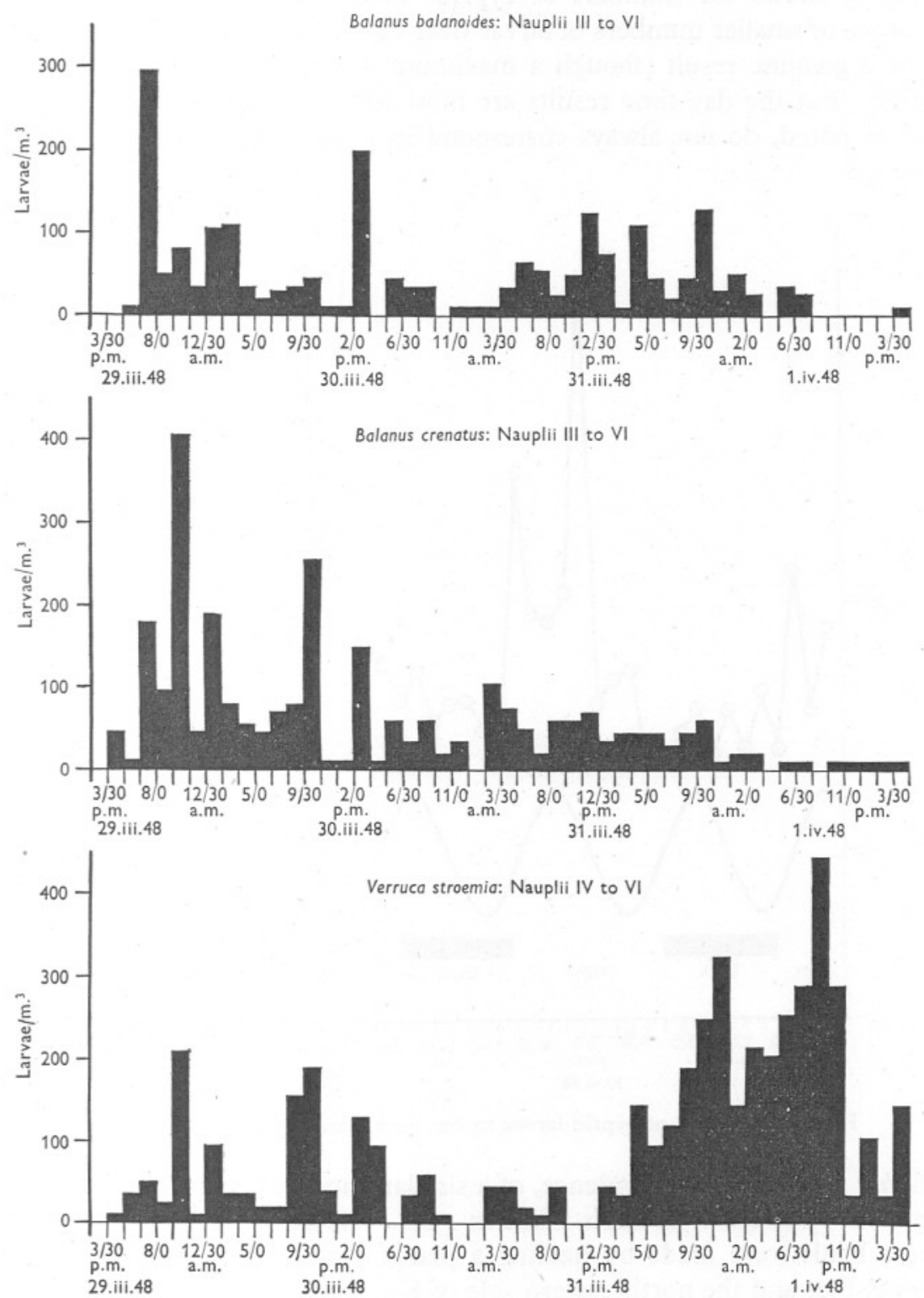

Fig. 4. Numbers of later-stage nauplii, separated into species, for the third set of serial hauls. 
Fig. 5 shows the numbers of cyprids obtained in each haul. Here the presence of smaller numbers of larvae near the surface during the night seems to be a genuine result (though a maximum did occur just after dark on $3 \mathrm{I}$ March), but the day-time results are most irregular. The cyprid maxima, it will be noted, do not always correspond in time with the naupliar maxima (Fig. 3).

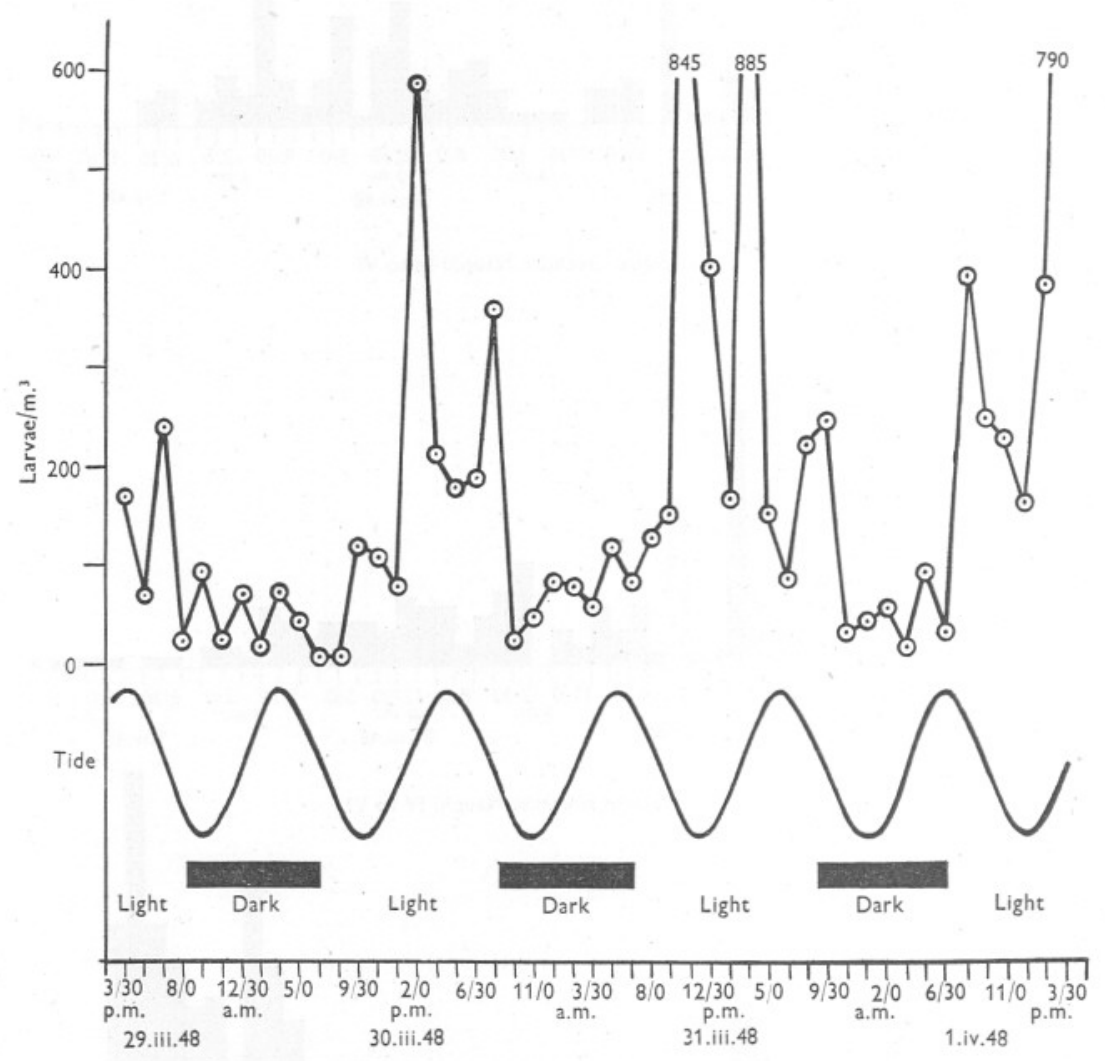

Fig. 5. Numbers of cyprid larvae in the serial hauls of 29 March-I April.

Other series. Further evidence, of a similar nature to that just described, is provided by two sets of hauls made in 1944. The results are shown in Fig 6 . These hauls were made by hauling a plankton net across the bay between Keppel Pier and the north-eastern side of Keppel Point, a distance of roughly $500 \mathrm{ft}$. The numbers of larvae recorded are not given as numbers $/ \mathrm{m}^{3}$ as these hauls cannot be considered as quantitative. The towing speed used was roughly one knot, but the relative speed of the net varied with the state of the tide. This factor was important because the towing speed was roughly the same as that of the ebb tidal current. An attempt was made to convert the figures 
obtained to numbers $/ \mathrm{m}^{3}$, assuming that the fishing efficiency of the net was $100 \%$ throughout and that the mouth of the net remained normal to the current throughout the run. The results obtained, however, were so low in comparison with those recorded from the pump hauls just described, as to indicate that these assumptions were not valid.
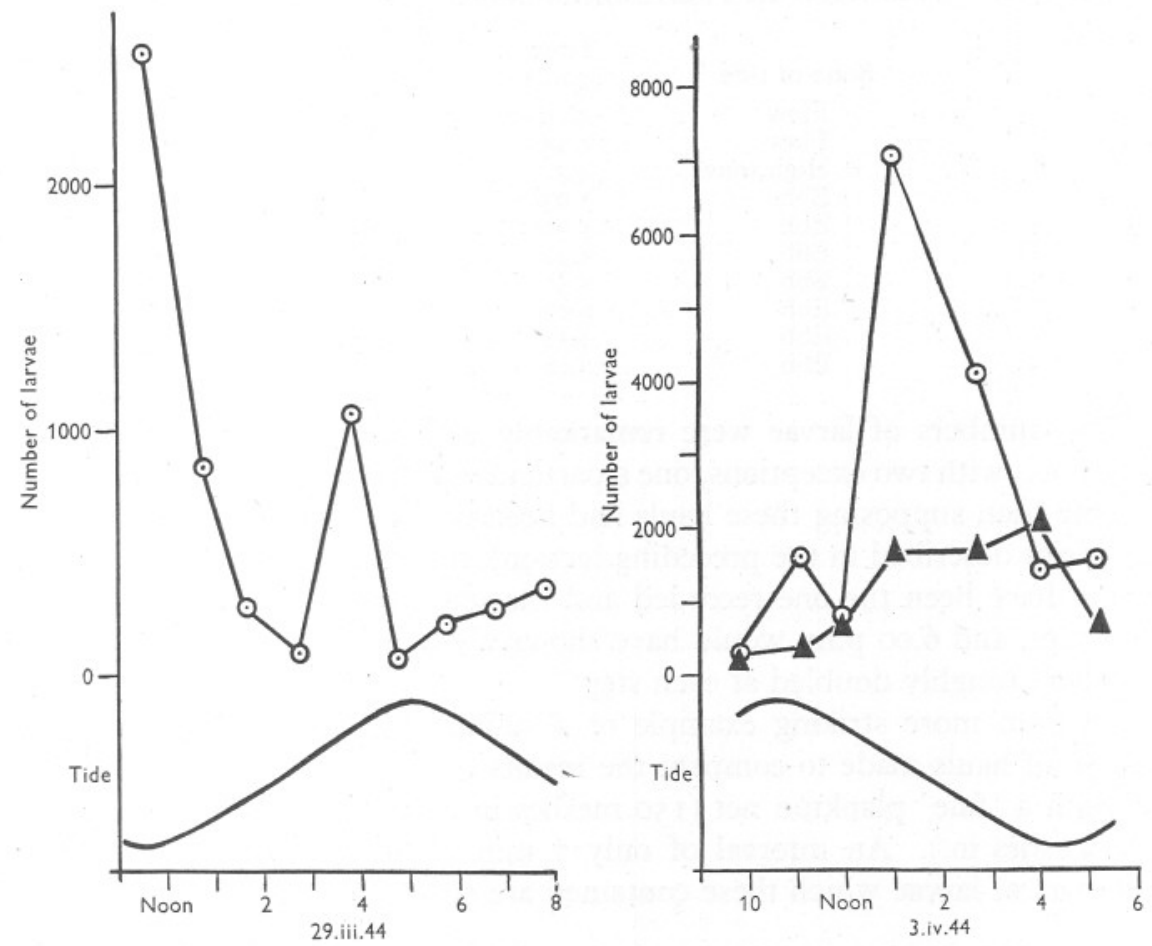

Fig. 6. Total barnacle larvae in the serial hauls of 29 March 1944 and 3 April I944. $\odot-\odot$ Stages I-VI, $\mathbf{A}-\mathbf{\Delta}$ Cyprid.

The first of this series of hauls was made on 29 March, when many late-stage nauplii and a few cyprids were present; the second was made 5 days later, when cyprids were more abundant. The results obtained on 29 March suggest a maximum number of nauplii at low water and possibly a minimum at high water, but they were contradicted by those obtained on 3 April, when numbers were low both at high and at low water, and a maximum occurred during the ebb. The cyprid maximum, which was ill-defined, occurred at low water.

\section{Supplementary Hauls}

In the intervals between the sets of serial hauls described in the last section, a number of other hauls were made, to test the reproducibility of the samples obtained. 
One test of this kind was made on I6 March and the results are shown in Table II. It was designed both to investigate how much the larval population varied over very short periods and to compare the results of pump hauls with those of hauls made simultaneously from the pier.

\section{Table II. Variation in Naupliar Numbers over Very Short Periods}

$\begin{array}{lcc}\text { State of tide } & \begin{array}{c}\text { Time } \\ \text { (p.m.) }\end{array} & \text { Nauplii } / \mathrm{m}^{3} \\ \text { Flow } & 3.00 & 455 \\ \text { Flow } & 3.45 & 715 \\ \text { High water } & 4.32 & 905 \\ \text { Ebb } & 5.03 & 910 \\ \text { Ebb } & 5.36 & 930 \\ \text { Ebb } & 5.42 & 610 \\ \text { Ebb } & 5.57 & 2060 \\ \text { Ebb } & 6.08 & 925 \\ \text { Ebb } & 6.18 & 935 \\ \text { Ebb } & 6.26 & 910\end{array}$

The numbers of larvae were remarkably uniform after the haul made at 4.32 p.m., with two exceptions, one a particularly striking one. It is interesting to note that, supposing these hauls had been taken at $90 \mathrm{~min}$. intervals (as in the series described in the preceding section), the exceptional haul (5.57 p.m.) would have been the one recorded and the sequence of readings, 3.00 p.m., 4.30 p.m. and 6.00 p.m. would have shown a convincing rise, with the larval numbers roughly doubled at each step.

An even more striking example of a sudden variation was found in the course of hauls made to compare the results obtained by pumping the water through a 'fine' plankton net (I 50 meshes/in.) and through a 'medium' net (50 meshes/in.). An interval of only $7 \mathrm{~min}$. separated the two hauls; the numbers of larvae which these contained are shown in Table III.

Table III. Numbers of Naupli from Water Pumped through 'Fine' AND 'Medium' Nets (I7 MarCh)

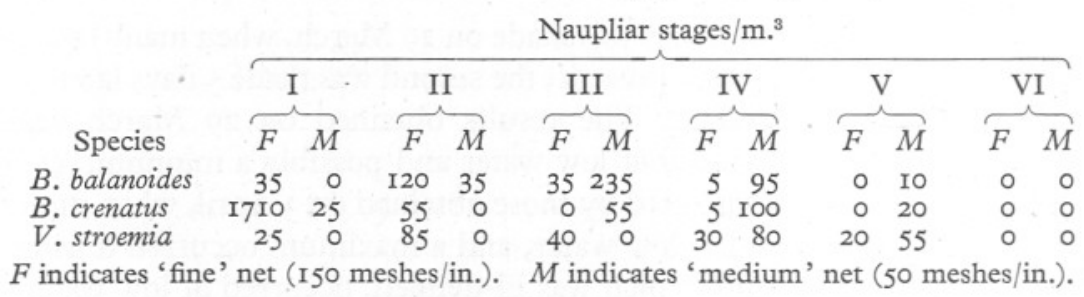

It was to be expected that the numbers of the early-stage nauplii would be greater from the 'fine' than from the 'medium' net, but there would seem no reason, except a variation in the larval population, why the numbers of laterstage larvae should vary so markedly, since they should be retained by both nets. It should be added that, as only an aliquot part of each haul was counted, 
the smaller variations shown in Table III are probably not significant, but some of the variations (e.g. those of the 4 th-stage nauplii) seem great enough to be independent of a sampling error.

Other hauls made in rapid succession indicate that sudden variations can also occur in the numbers of cyprid larvae (Table IV).

TAble IV. Variation IN Cyprid Numbers OVER Very
Short Periods (2 APriL)
$\begin{array}{cc}\text { Time of haul } \\ \text { (p.m.) } & \text { Cyprids/m. }{ }^{3} \\ 3.24 & 845 \\ 3.30 & 1305 \\ 3.35 & 730 \\ 3.39 & 1350 \\ 3.43 & 1490\end{array}$

As many of the maxima shown in Figs. I-5 are isolated points, unsupported by a graded series of records on either side, it is evident that the results just quoted suggest that any maximum should be regarded with considerable suspicion, since its occurrence may merely be a matter of chance rather than an indication of diurnal or tidal variation. Though it would therefore seem reasonable to discount many of the maxima recorded in these figures, the situation is possibly not the same for the evidence of diurnal variation in the numbers of larval stages in the surface water. There is some consistent evidence for the reduction in the numbers of all the larval stages in the surface waters during the hours of darkness and this effect is perhaps most strikingly shown for the cyprids of Balanus balanoides.

It is possible that the sudden variations just discussed are due to sampling errors rather than to a true variation in larval numbers. The water was pumped through a net and errors may have arisen because all the catch was not always transferred to the collecting jar. Every effort was made to adopt a similar procedure at each collection, so a significant error would appear to be unlikely. A number of hauls were made in which $\mathrm{I} \mathrm{m} .^{3}$ was pumped through the net in successive thirds. The variations in the numbers of larvae from these hauls were of a similar order to those from hauls in which only $0.3 \mathrm{~m} . .^{3}$ of water was passed through the net. If the cause of the sudden variations had been a sampling error, this grouping of hauls into threes should have accentuated this effect, whereas no indications of accentuation were found.

It must therefore be concluded that sudden variations in the numbers of barnacle larvae do occur and that therefore the results of single hauls may be misleading. 


\section{Comparisons of Net and Pump Hauls}

Plankton nets, both 'fine' and 'medium', were fished from Keppel Pier whenever an opportunity arose during the course of these series of pump hauls. A number of instances are thus available for comparisons between the two methods.

Qualitative comparisons are set out in Table V, in which the percentage composition of the net haul is compared with that of pump hauls made immediately before and immediately after the period for which the nets were fished.

There is evidently a rough qualitative equivalence between the pump and net hauls in spite of the sudden variations which may exist between successive pump hauls. Sometimes considerable differences between the two methods of collection do occur, however (e.g. those on 3I March), and these may be due to the incidence of this factor.

\section{Table V. Qualitative Comparisons between Pump and Net Hauls}

\begin{tabular}{|c|c|c|c|c|c|c|c|c|c|}
\hline \multirow[b]{3}{*}{ Date } & \multicolumn{9}{|c|}{ Percentage composition of haul } \\
\hline & \multicolumn{3}{|c|}{ B. balanoides } & \multicolumn{3}{|c|}{ B. crenatus } & \multicolumn{3}{|c|}{$V$. stroemia } \\
\hline & $P_{1}$ & $N$ & $P_{2}$ & $P_{1}$ & $N$ & $P_{2}$ & $P_{1}$ & $N$ & $P_{2}$ \\
\hline II March & $8 \mathrm{I} \cdot 7$ & $73 \cdot 6$ & $72 \cdot 7$ & $6 \cdot 3$ & $8 \cdot 7$ & $9 \cdot 2$ & $\mathrm{I} 2 \cdot 0$ & $17 \cdot 7$ & I $8 \cdot I$ \\
\hline I2 March & $55^{\circ} 0$ & $40 \cdot 9$ & $37 \cdot 0$ & $23 \cdot I$ & $2 \cdot 4$ & $27 \cdot 0$ & $2 I \cdot 9$ & $56 \cdot 7$ & 36.0 \\
\hline 24 March & $76 \cdot 8$ & $77 \cdot 2$ & $72 \cdot 5$ & 18.5 & II $\cdot 9$ & I7 & $4 \cdot 6$ & 10.9 & $10 \cdot 0$ \\
\hline 29 March & $62 \cdot 0$ & 63.9 & $66 \cdot 6$ & 13.8 & 19.8 & $26 \cdot 9$ & $24 \cdot 2$ & $16 \cdot 3$ & 6.5 \\
\hline $30 \mathrm{March}$ & $59 \cdot 6$ & $5 \mathrm{I} \cdot \mathrm{I}$ & $66 \cdot 6$ & $36 \cdot 6$ & 25.9 & $25 \cdot 2$ & $3 \cdot 8$ & $23 \cdot 0$ & $8 \cdot 2$ \\
\hline 3 I March & 16.4 & $72 \cdot I$ & $4 I \cdot 3$ & $78 \cdot 3$ & 10.9 & $50 \cdot 0$ & $5 \cdot 3$ & I6. I & $8 \cdot 7$ \\
\hline 6 April & 83.7 & $86 \cdot I$ & $44 \cdot 6$ & $17 \cdot 3$ & 13.9 & 54.7 & 0 & 0 & 0.7 \\
\hline 8 April & $5 I .6$ & $5 \mathrm{I} \cdot 0$ & $4 \mathrm{I} \cdot 6$ & $43 \cdot 4$ & $47 \cdot \mathrm{I}$ & 54.0 & $5 \cdot 0$ & $I \cdot 9$ & $4 \cdot 4$ \\
\hline Average & 60.9 & $64: 5$ & $55 \cdot 4$ & $29 \cdot 7$ & $\mathrm{I} 7 \cdot 6$ & $33 \cdot I$ & 9.6 & $17 \cdot 8$ & II 6 \\
\hline
\end{tabular}

$P_{1}$ indicates the pump haul made just before the net haul $(N), P_{2}$ the pump haul made just after the net haul.

These qualitative comparisons are taken a stage further in Fig. 7, which shows the analyses of the net and pump hauls for II March and 8 April into the larval stages represented. The set for II March is more closely comparable than that for 8 April, but as the numbers of larvae present in the pump hauls for II March were considerably greater than those for 8 April, a closer correspondence in the former set was perhaps to be expected.

Quantitative comparisons indicate considerable differences between the numbers of larvae collected by the pump and by nets fished from the pier. It is not possible accurately to estimate the volume of water that passes, or could pass, through a net fished from the pier, but if it is assumed that the current through the pier during the ebb runs at a speed of I knot and that all this water passes through the net, then the volume filtered is approximately $365 \mathrm{~m} .^{3}$. It is probable that all the water does not pass through the net, but as 
the estimate of current speed is a conservative one (a good ebb will run at a speed of just over 2 knots at Keppel Pier) this allows for some error in the assumption that all the water is filtered through the net.

On these assumptions, comparisons between pump and net hauls have been made and the results are shown in Table VI. The first two estimates in this table were made at a time when Skeletonema was very abundant; this was probably an important factor in producing the low fishing efficiencies recorded.



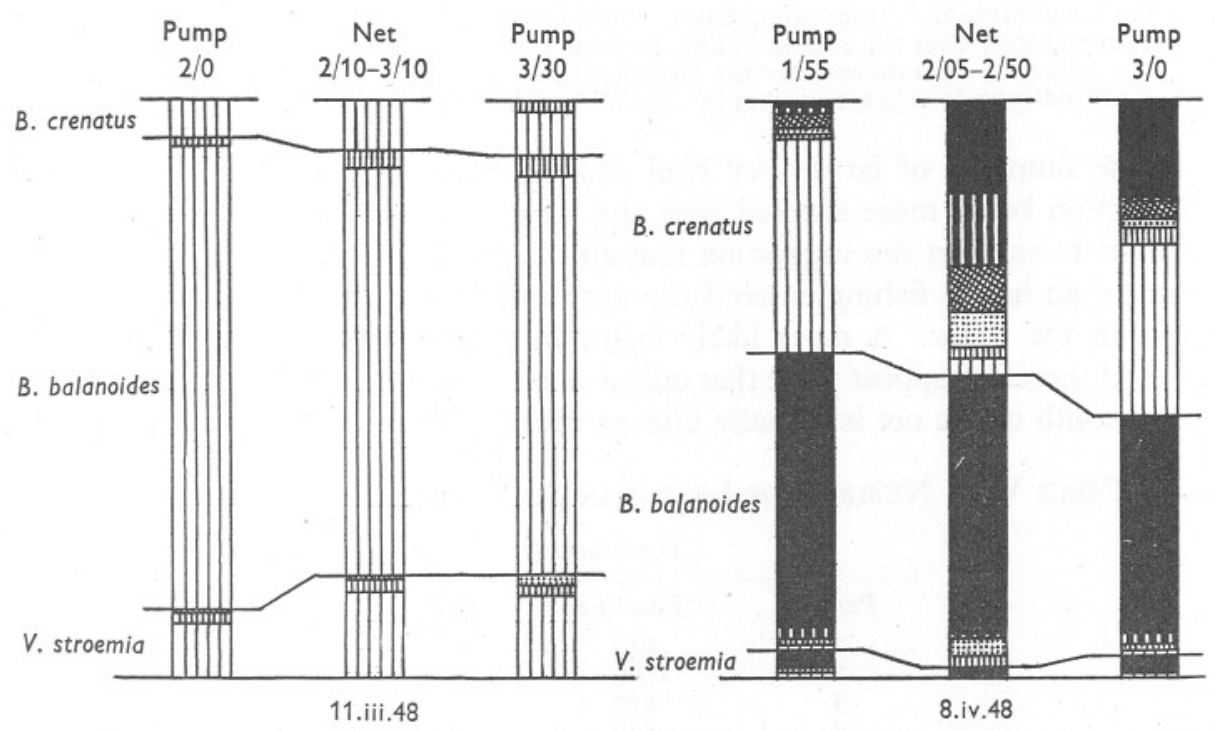

Fig. 7. Analysis of net and pump hauls on II March and 8 April.

Though the last three estimates are based on the net hauls from both 'fine' and 'medium' nets, roughly $95 \%$ or more of the larvae recorded came from the 'medium' net, so that the fishing efficiencies given may be taken as those of the latter net only.

During a period when diatoms are abundant in the water, clogging of the mesh of the net is doubtless an important factor in reducing fishing efficiency, but at other times clogging of the mesh does not seem to be the most important factor in reducing this efficiency. Nets have usually been fished from the pier for $\mathrm{I} \mathrm{hr}$. and if clogging were a significant factor the numbers of larvae caught, 
for example, during the first Io min. should be much greater than those caught during the last Io min. of this immersion period. The experiment was therefore made of subdividing the fishing period into five periods, each of $10 \mathrm{~min}$. duration. At the end of each fishing period, the net was carefully withdrawn and the collecting jar changed with the minimum of disturbance. The results of these hauls are shown in Table VII.

\section{Table VI. Fishing Efficiency of Plankton Nets}

$\begin{array}{clcccc}\text { Date } & \text { Range of tide } & \begin{array}{c}\text { Total } \\ \text { larvae/m. } \\ \text { (from pump) }\end{array} & \begin{array}{c}\text { Total larvae } \\ \text { (from net) }\end{array} & \begin{array}{c}\text { Theoretical } \\ \text { total larvae } \\ \text { from net }\end{array} & \begin{array}{c}\text { Fishing } \\ \text { efficiency } \\ (\%)\end{array} \\ \text { II March } & \text { Spring } & 8820 & 24,200 & 3,220,000 & 0 \cdot 75(F) \\ \text { I2 March } & \text { Spring } & 5270 & 5,870 & 1,923,000 & 0.30(F) \\ \text { 24 March } & \text { Neap/Spring } & 315 & 45,460 & 229,900 & 24 \cdot 9(F+M) \\ \text { 30 March } & \text { Spring/Neap } & 540 & 47,400 & 394,200 & \text { I2.0 }(F+M) \\ \text { 6 April } & \text { Neap/Spring } & 1040 & 38,980 & 759,100 & 5 \cdot 1(F+M)\end{array}$

The total larvae $/ \mathrm{m}^{3}$ (from pump hauls) is the average of the haul immediately before and that immediately after the corresponding net haul.

The letters in parentheses after the estimates of fishing efficiency indicate the type of net used; $F$ indicates 'fine' ( 50 meshes/in.) and $M$ indicates a 'medium' net (50 meshes/in.).

The numbers of larvae per haul showed a decrease with both nets, the reduction being more marked with the 'fine' net, but there is little in these results to support the suggestion that all the larvae which are recorded at the end of an hour's fishing entered the net in the first few minutes that the net was in the water. A more likely factor in producing low fishing efficiency would therefore appear to be that only a small proportion of the water reaching the mouth of the net is actually filtered through its mesh.

\section{Table VII. Numbers of Larvae in Successive io min. Net Hauls}

\begin{tabular}{ccc}
\multicolumn{3}{c}{ Total larvae } \\
Period & 'Fine' net & 'Medium' net \\
I & 940 & 3370 \\
2 & 1700 & 3160 \\
3 & 470 & 3460 \\
4 & 420 & 2960 \\
5 & 360 & 2220
\end{tabular}

\section{Discussion}

Weiss (1947) has recently investigated the rate of attachment of the cyprids of Balanus improvisus and finds that, for this species, there is a definite diurnal variation, attachment taking place more by day than by night. If the number of attachments over a given period is proportional to the number of larvae present in the surface water, then the results of the present study would suggest that the same was true for B. balanoides, as the cyprids of this species were more plentiful in the surface waters during the day. It was hoped that it 
would be possible to supplement these planktonic investigations by observations on the amount of settlement on collectors exposed on Keppel Pier, but the numbers which attached were too small to allow this direct test to be made.

Diurnal variations in the numbers of cyprids in the surface water is one of the few definite results that have emerged from this investigation as it was originally planned, though it seems likely that all the larval stages, at least of $B$. balanoides and B. crenatus, also show some diurnal variation. Weiss (I947) also found that, during the day, the greatest numbers of cyprids attached during the low tide period. No regular variation with tidal state was found for the occurrence of the three species present in the hauls made in the present series, but this difference does not necessarily imply a difference in habit, since Weiss makes it clear that the variation he found seemed to be due to the geographical conditions of his experimental site.

The sudden variations which occur in larval numbers have been clearly shown by these counts of pump hauls; this phenomenon seems to be common to all the stages of the three species of barnacles. Fluctuations between hauls taken in rapid succession have, in the present investigation, probably been emphasized because the volume of water filtered was so small, but their persistence when the volume filtered was trebled and their occurrence in the early stages of the investigation, when the numbers of larvae present were much greater, suggests that the phenomenon cannot wholly be attributed to inadequacy of sampling.

The hauls collected by nets from the pier seem to give a reasonable qualitative impression of the various species and stages of barnacle larvae present in the plankton. As these nets are fished for periods much longer than those required to take a pump haul, the results they give are, in one respect, more reliable than those given by the pump hauls, namely that the longer fishing period will tend to obliterate the sudden fluctuations which characterize the shorter fishing periods. This advantage is certainly outweighed by the low fishing efficiency of the nets themselves.

The low fishing efficiency of the nets seems likely to be produced because only a small proportion of the water which is carried to the mouth actually enters the net. The low fishing efficiencies recorded suggest that the speed of the ebb tidal current may be reduced, near the mouth of the net, to a value which is not far removed from the rate of swimming of the larvae. This may mean that certain stages, or certain species, may be able to avoid capture. In this connexion, it is of interest to note the results presented in Table V (p. 364). The numbers of $B$. crenatus larvae caught in the net are less than those taken by the pump (this difference is mainly due to the increased numbers of Istand 2nd-stage nauplii in the latter hauls) and the numbers of Verruca stroemia larvae caught by the net are greater than those taken in the pump. No significant differences, however, occur between the pump and net hauls of the larvae of Balanus balanoides. These differences may be due to biological factors 
such as differences in the rate of swimming or differences in rheotropism; further work on this point may well be interesting.

It should be added that the estimates of fishing efficiency quoted earlier, as they have been expressed numerically, probably give too definite an impression of the results achieved. Considerable variations in fishing efficiency are possible between two successive immersions of the same net, so that an extended series of determinations would have to be made to establish the fishing efficiency of a given net at all firmly.

Biologically, the difference in fishing efficiency between the fine and medium nets is important because it obscures the numerical differences between the various larval stages. The early-stage nauplii chiefly appear in fine net hauls, whereas the later-stage nauplii and cyprids chiefly appear in the hauls made with the medium net. As the fishing efficiency of a medium net appears to be as much as eighty times greater than that of a fine net, an incorrect impression of larval mortality and dispersal during the sequence from hatching to settlement is obtained. Table VIII, below, gives the highest numbers of each larval stage of each species recorded during the present series of pump hauls.

Table VIII. Highest Numbers of Larval Stages (NUMBER $/ M^{3}{ }^{3}$ ) FROM PUMP HAULS

\begin{tabular}{|c|c|c|c|c|c|c|c|}
\hline & & & & $\mathrm{ral} \mathrm{s}$ & & & \\
\hline & & & Nau & & & & \\
\hline Species & I & II & III & IV & V & $\mathrm{VI}$ & Cyprid \\
\hline B. balanoides & I I 2,570 & 10,285 & 235 & 230 & 350 & 230 & 1085 \\
\hline B. crenatus & 3,430 & 2,000 & 70 & I90 & 70 & 70 & 145 \\
\hline$V$. stroemia & 2,285 & 915 & 995 & 285 & 430 & 60 & 65 \\
\hline
\end{tabular}

These results suggest that roughly $\mathrm{I} \%$ of the larvae of $B$. balanoides which are hatched survive to become cyprids, roughly $9 \%$ of the larvae of $B$. crenatus and roughly $3 \%$ of the larvae of Verruca stroemia complete the larval sequence. This is, however, only the crudest approximation, since it leaves out of account the life period of each larval stage (this is possibly the reason why the cyprid numbers are higher than those of the 6th-stage nauplii), and it also assumes that the three species can be fairly compared. This is probably not true, as these pump hauls were started at a time when the larvae of Balanus balanoides were hatching, and thus very large numbers of the early-stage larvae of this species were recorded, but the pump hauls were started too late to record the corresponding hauls of the early-stage larvae of $B$. crenatus and Verruca stroemia. 


\section{SUMMARY}

Records are given of the numbers of barnacle larvae obtained from samples of water pumped through a plankton net. Several series of hauls were made at intervals over the time of year when barnacle larvae are abundant.

The numbers of the cyprid larvae of Balanus balanoides in the surface waters show a diurnal variation, being markedly less during the hours of darkness. This conclusion may also apply to the cyprids of $B$. crenatus and Verruca stroemia, but the numbers of these larvae were too small to permit reliable conclusions to be drawn. There is some evidence that similar diurnal variations occur in larval stages other than the cyprid.

The numbers of larvae present in the surface waters during the day showed marked variations which were not correlated with tidal state. Pump hauls made within a few minutes of each other showed comparable variations.

Comparison of the hauls made using the pump and those from nets fished in the ebb tide suggest that the latter give an adequate qualitative record of the barnacle larval stages present, but are inadequate quantitatively. The fishing efficiency of a 'fine' net (I50 meshes/in.) is very low, values of less than I \% being recorded, and that of a 'medium' net ( 50 meshes/in.) is not high, the maximum value recorded for this type of net being roughly $25 \%$. There are indications that loss of fishing efficiency is produced by water not entering the net rather than by clogging of the mesh. The latter factor is undoubtedly important, however, in producing the very low fishing efficiency of a 'fine' net during a period of diatom abundance.

The difference in fishing efficiency between 'fine' and 'medium' nets affects estimates of the numbers of each of the larval stages present, since most of the early-stage nauplii appear in 'fine' net hauls, whereas most of the later-stage nauplii appear in 'medium' net hauls. Pump hauls seem likely to present a more accurate record and estimates of the success of the larval sequence based on these hauls suggests that only $\mathrm{I} \%$ of the first-stage nauplii may complete the full sequence of development to the cyprid stage.

\section{REFERENCES}

Gibbons, S. G. \& Fraser, J. H., 1937. The centrifugal pump and suction hose as a method of collecting plankton samples. Fourn. Conseil Explor. Mer, Vol. xII, pp. $155-70$.

MOORE, H. B., I935. The biology of Balanus balanoides. III. The soft parts. Fourn. Mar. Biol. Assoc., Vol. xx, pp. 263-77.

Pyefinch, K. A., I948. Notes on the biology of Cirripedes. Fourn. Mar. Biol. Assoc., Vol. xxvII, pp. 464-503.

WEISs, C. M., I947. The effect of illumination and stage of tide on the attachment of barnacle cyprids. Biol. Bull. Woods Hole, Vol. xcIII, pp. 240-49.

WIBORG, K. F., I948. Experiments with the Clarke-Bumpus plankton sampler and with a plankton pump in the Lofoten area in Northern Norway. Fiskeridirektoratets Skriften, Vol. Ix, No. 2. 